\begin{tabular}{ll|l}
\hline Bentham OPEN & The Open Biotechnology Journal \\
\hline CrossMark & Content list available at: www.benthamopen.com/TOBIOTJ/ & DOI: $10.2174 / 1874070701811140282,2018,12,282-287$ \\
Thioctennology \\
lournal
\end{tabular}

RESEARCH ARTICLE

\title{
Ochratoxin A Removal by Lactobacillus Plantarum V22 in Synthetic Substrates
}

\author{
Moncalvo A. ${ }^{1}$, Dordoni R. ${ }^{1}$, Silva A. , Fumi M.D. ${ }^{1}$, Di Piazza S. ${ }^{2}$ and Spigno G. ${ }^{1, *}$ \\ ${ }^{I}$ DiSTAS Department for Sustainable Food Process, Università Cattolica del Sacro Cuore, Via Emilia Parmense 84, \\ 29122 Piacenza, Italy \\ ${ }^{2}$ Laboratory of Mycology, Department of Earth, Environmental and Life Sciences, Università degli Studi di Genova, \\ Corso Europa 26, I, 16136 Genova, Italy
}

Received: September 30, 2018

Revised: October 25, 2018

Accepted: November 11, 2018

\begin{abstract}
:
Background:

Ochratoxin $\mathrm{A}$ is a nephrotoxin which may occur in wines characterised by higher $\mathrm{pH}$ than the average. In the last decades the mechanisms responsible for ochratoxin A reduction by lactic acid bacteria have been investigated and identified as mainly cell walls adsorption and / or enzymatic conversion to ochratoxin- $\alpha$, a non-toxic metabolite. Since lactic acid bacteria are involved in the malolactic fermentation during the wine-making process, selected starter cultures could be exploited to guarantee safe ochratoxin A level in wines also from contaminated grapes. A lactic acid bacteria strain (Lactobacillus plantarum V22) was previously selected for its ability of both degrading ochratoxin A and carrying out malolactic fermentation at high $\mathrm{pH}$.
\end{abstract}

\section{Objective:}

This study was aimed at assessing if the selected L. plantarum strain, can reduce ochratoxin A because it can use it as a carbon source.

\section{Methods:}

L. plantarum V22 was grown in the presence of ochratoxin A in two different synthetic substrates, with or without malic acid, monitoring the reduction of ochratoxin A and the presence of ochratoxin $\alpha$ as an indicator for a toxin enzymatic hydrolysis. The presence of residual not hydrolysed ochratoxin A bound to the bacteria cell walls was also evaluated to quantify the ochratoxin A removal due to simple adsorption.

\section{Result:}

A significant reduction of $19.5 \pm 2.0 \%$ in ochratoxin A concentration was observed only in the presence of malic acid. The quantified fraction of ochratoxin A adsorbed on cell walls was irrelevant and the metabolite ochratoxin $\alpha$ could not be detected.

\section{Conclusion:}

There is a possibility that L. plantarum V22 can degrade ochratoxin A through a not yet identified metabolic pathway.

Keywords: Bio-decontamination, Lactobacillus plantarum, Malolactic fermentation, Ochratoxin A, Wine, Synthetic Substrates.

\footnotetext{
"Address correspondence to this author at the DiSTAS Department for Sustainable Food Process, Università Cattolica del Sacro Cuore, Via Emilia Parmense 84, 29122 Piacenza, Italy; Tel: +39 0523 599181; E-mail: giorgia.spigno@unicatt.it
} 


\section{INTRODUCTION}

Ochratoxin A (OTA) is a secondary metabolite of moulds and one of the most common contaminating agents in raw materials and food products. It is a well-known nephrotoxin for different species, classified as possible human carcinogen by IARC [1].

OTA was identified in grape juices and wines for the first time in 1996 [2]. After that, several approaches have been tested to reduce this toxin in grape and to remove it during winemaking [3, 4]. A maximum residual contamination level in wine of two parts-per-billion ( $\mathrm{ppb}, \sim 2 \mu \mathrm{g} / \mathrm{L}$ ) was established by the European Union (Commission Regulation No. 1881/2006). In red winemaking process, OTA concentration increases during maceration as an effect of prolonged contact between skins and must. However, operations such as clarification and filtration, and processes as Malolactic Fermentation (MLF), can allow for a relevant decrease [5]. MLF is carried out by lactic acid bacteria and OTA degradation by LAB has also been investigated [6], showing that LAB can hydrolyse (through a carboxypeptidase) OTA in L-phenylalanine and OT $\alpha$, a non-toxic metabolite [7].

OTA can be particularly found in musts and wines from specific regions of Europe as southern Italy, Greece and Spain [8]. Furthermore, wines from these regions are characterized by higher $\mathrm{pH}$ values which can negatively affect MLF [9].

Several approaches have been tested to reduce the occurrence of OTA in grape and to remove the toxin during winemaking [10 - 12]. During red winemaking process the OTA concentration increases in maceration probably due to prolonged contact between skins and must, but the balance of OTA in wine during winemaking is overall negative because operations as clarification and filtration, and processes as MLF cause a relevant decrease of this mycotoxin. The use of selected bacterial strains for OTA reduction in winemaking requires further studies because the available literature is limited. In fact, although many studies were carried out on adsorption process by yeasts during winemaking [13 - 15], the degradation process by LAB and its mechanisms have been little investigated. Rodriguez et al. [16] investigated the capability to hydrolyse OTA in some Brevibacterium species finding that different strains of $B$. casei, B. linens, B. iodinum and B. epidermidis were able to completely degrade OTA in OT $\alpha$ (in basal salt medium with 40 $\mu \mathrm{g} / \mathrm{L}$ OTA). Abrunhosa et al. [17] showed that in Man Rogosa Sharpe (MRS) with $1 \mu \mathrm{g} / \mathrm{mL}$ OTA, Pediococcus parvulus strains were able to degrade OTA in OT $\alpha$, while L. plantarum reduced OTA concentration by $10-14 \%$ (without forming OT $\alpha$ ).

A selection program of malolactic starter culture capable of degrading OTA in wine, driven by the former Institute of Oenology and Agro-Food Engineering of the Università Cattolica del Sacro Cuore of Piacenza (Italy), led to the identification of a Lactobacillus plantarum strain (V22 ${ }^{\mathrm{TM}}$ Lactobacillus plantarum, Lallemand) with demonstrated ability to carry out MLF especially in wine with high $\mathrm{pH}$.

The aim of this work was to get some more insight into the mechanisms behind the reduction of OTA levels in wine by L. plantarum V22 to better exploit its use for bio-decontamination of wines with high OTA contents. We wanted to evaluate whether the strain can use OTA as carbon source at the end of MLF (when the L-malic acid is completely decarboxylated in L-lactic acid) or if the reduction can occur only during MLF.

\section{MATERIALS AND METHODS}

\subsection{Standards, Chemicals and Bacteria}

All solvent used for chromatographic analysis were of HPLC grade, OTA and OT $\alpha$ standards were from Biopure (Waterlooville, UK), MRS broth was purchased from Oxoid (Basingstoke, UK) and Agar was obtained from Bacto ${ }^{\mathrm{TM}}$ (Sparks, MD, USA). Yeast Nitrogen Base (YNB) without amino acids and ammonium sulfate was purchased from $\operatorname{Difco}^{\mathrm{TM}}$ (Sparks, MD, USA). L-malic acid was from Sigma-Aldrich (Merck).

The L. plantarum V22 was stored in glycerol at $-80^{\circ} \mathrm{C}$ in the laboratories of the DiSTAS of the Università Cattolica del Sacro Cuore of Piacenza (Italy). For the preparation of the inoculum for the planned trials, the strain was reactivated through growth in MRS broth for $48 \mathrm{~h}$ at $25^{\circ} \mathrm{C}$ under aerobic conditions. The cells were harvested by centrifugation at $6000 x \mathrm{~g}$ for $15 \mathrm{~min}$ at $4^{\circ} \mathrm{C}$, washed with and resuspended in sterilized physiological solution $(\mathrm{NaCl} 8.5 \mathrm{~g} / \mathrm{L})$. The cell content of this suspension was determined by turbidimetric measurement (optical density at $630 \mathrm{~nm}, \mathrm{OD}_{630}$, using a spectrophotometer UV-1601 UV-visible, Shimadzu) and using a calibration curve for OD $_{630}$ versus cell number concentration (determined by counting the cells at the optical microscope). The correspondence of total cell content with the content in colony forming units $(\mathrm{CFU} / \mathrm{mL})$ was verified by plate count on MRS-Agar, 2 days of incubation at 
$25^{\circ} \mathrm{C}$

\subsection{Ochratoxin A Removal Assay}

OTA removal was assessed in YNB containing all essential nutrients except amino acids, nitrogen and carbohydrate.

The synthetic substrate without L-malic acid (L-malic-) consisted in YNB $6.7 \mathrm{~g} / \mathrm{L}$ in water, $\mathrm{pH}$ adjusted at 3.8 using phosphoric acid $1 \mathrm{M}$. The substrate with L-malic acid (L-malic+) was obtained as the previous one adding $2 \mathrm{~g} / \mathrm{L} \mathrm{L}-$ malic acid.

OTA was added to both the substrates at a concentration of $25 \mu \mathrm{g} / \mathrm{L}$ (actual starting level was measured by HPLC analysis). Aliquots of $30 \mathrm{~mL}$ of different synthetic substrates were poured into $50 \mathrm{~mL}$ Falcon tubes and then inoculated with adequate volumes of the inoculum suspension of L. plantarum V22 inoculum to have an initial concentration of $10^{9} \mathrm{CFU} / \mathrm{mL}$.

Not-inoculated samples of L-malic+ substrate with OTA were prepared as negative control samples.

As positive control, B. linens able to degrade OTA without any other carbon source was tested in L-malic- [16].

All the prepared samples were kept at $25^{\circ} \mathrm{C}$ in a thermostatic incubator under anaerobic (closed Falcon tubes) and static condition. OT $\alpha$, OTA, and L-malic acid contents and total cell content (as $\mathrm{OD}_{630}$ ) were evaluated at inoculation time (time 0$)$ and after 3, 6 and 10 days. Total viable cell concentration $(\mathrm{CFU} / \mathrm{mL})$ was determined by plate count on MRS-Agar only at time 0 and after 10 days. $\mathrm{OD}_{630}$ and $\mathrm{CFU} / \mathrm{mL}$ were not evaluated for the positive control.

For the analysis of OT $\alpha$, OTA and L-malic acid, the biomass and supernatant were separated by centrifugation at $6000 \mathrm{xg}$ for $15 \mathrm{~min}$ at $4^{\circ} \mathrm{C}$. The supernatant was filtered $(0.45 \mu \mathrm{m})$ and directly analysed for OT $\alpha$, OTA (by HPLC) and for L-malic acid (by L-malic acid assay kit, Megazyme, Wicklow, Ireland).

The biomass pellet was rinsed two times with water, dried and then suspended in $2 \mathrm{~mL}$ of absolute methanol for $1 \mathrm{~h}$. After centrifugation at $6000 x \mathrm{~g}$ for $15 \mathrm{~min}$ at $4{ }^{\circ} \mathrm{C}$, methanol was separated, collected in $5 \mathrm{~mL}$ vials and evaporated to dryness under dry nitrogen gas stream. For evaluation of OTA and OT $\alpha$ contents by HPLC, the dry residue was reconstituted with the HPLC mobile phase immediately before analysis.

\subsection{Chromatographic Analysis}

Chromatographic analysis was performed on a HPLC system consisting of a Perkin Elmer (Norwalk, CT, USA) instrument equipped with a 200 Series pump, a Perkin-Elmer 650-10S fluorescence detector, a Jasco LC-Net II/ADC (Oklahoma City, OK, USA) communication module and operated by ChromNAV Control Center software. OTA and OT $\alpha$ were separated as described in Muñoz et al. [7] using a Gemini C18 column $250 \mathrm{~mm} \times 4.6 \mathrm{~mm}$ fitted with $5 \mu \mathrm{m}$ (Phenomenex). The analysis was carried out at room temperature with an injection volume of $20 \mu \mathrm{L}$. The mobile phases consisted of water/acetic acid $(98: 2 \mathrm{v} / \mathrm{v})($ phase A) and acetonitrile/acetic acid $(98: 2 \mathrm{v} / \mathrm{v})$ (phase B) eluted at a flow rate of $1.0 \mathrm{~mL} / \mathrm{min}$. Stepwise gradient was: 0-5 min 25\% B, 5-10 min 25-30\% B, 10-18 min 30-52\% B, 18-23 min 52\% B, 23-31 $\min 52-75 \% \mathrm{~B}, 31-36 \min 75-100 \% \mathrm{~B}, 36-41 \min 100 \% \mathrm{~B}, 41-44 \min 100-25 \% \mathrm{~B}, 44-54 \min 25 \% \mathrm{~B}$. Fluorescence detector was set at $333 \mathrm{~nm}$ excitation and $460 \mathrm{~nm}$ emission wavelengths.

\subsection{Statistical Analysis}

Experiments were carried out in duplicate, and the analyses were performed in triplicate. Results were expressed as means \pm standard deviation. The influence of the substrate and time on $\mathrm{OD}_{630}$, OTA and malic acid concentration was evaluated by one-way Analysis of Variance (ANOVA) using statistical software SPSS ${ }^{\circledR}$ (version 19.0, SPSS Inc., Chicago, IL, USA). Differences at $\mathrm{p} \leq 0.05$ were considered significant and in case of significant difference, the means were discriminated applying the post-hoc Tukey's test $(\mathrm{p} \leq 0.05)$.

\section{RESULTS AND DISCUSSION}

There was no significant influence of malic acid presence on neither cell concentration $\left(\mathrm{OD}_{630}\right)$ nor its trend over time (Table 1). 
Table 1. Bacterial cell count $\left(\mathrm{OD}_{630}\right)$ into $\mathrm{L}$-malic- and $\mathrm{L}$-malic+ substrates. Data represent mean values \pm standard deviations. Different letters indicate significant differences between samples, as assessed by ANOVA $(p \leq 0.05)$.

\begin{tabular}{|c|c|c|}
\hline \multirow{2}{*}{ Days } & \multicolumn{2}{|c|}{ OD $_{630}$} \\
\cline { 2 - 3 } & L-malic + & L-malic- \\
\hline 0 & $0.9255 \pm 0.0021^{\mathrm{a}}$ & $0.9235 \pm 0.0064^{\mathrm{a}}$ \\
\hline 3 & $0.8025 \pm 0.0078^{\mathrm{b}}$ & $0.7895 \pm 0.0078^{\mathrm{b}}$ \\
\hline 6 & $0.7705 \pm 0.0092^{\mathrm{b}}$ & $0.7675 \pm 0.0276^{\mathrm{b}}$ \\
\hline 10 & $0.6705 \pm 0.0403^{\mathrm{c}}$ & $0.6445 \pm 0.0290^{\mathrm{c}}$ \\
\hline
\end{tabular}

Cell concentration significantly decreased since the beginning indicating, as expectable, that the synthetic medium represents stressful conditions due to the lack of nutrients. However, evaluation of cell viability after 10 days, showed a higher level in L-malic $+\left(1.3 \times 10^{6} \mathrm{CFU} / \mathrm{mL}\right)$ than in L-malic- $\left(1.2 \times 10^{3} \mathrm{CFU} / \mathrm{mL}\right)$, confirming that L-malic acid is used as a carbon source. L-malic acid was degraded almost completely in 3 days by L. plantarum V22 (Fig. 1).

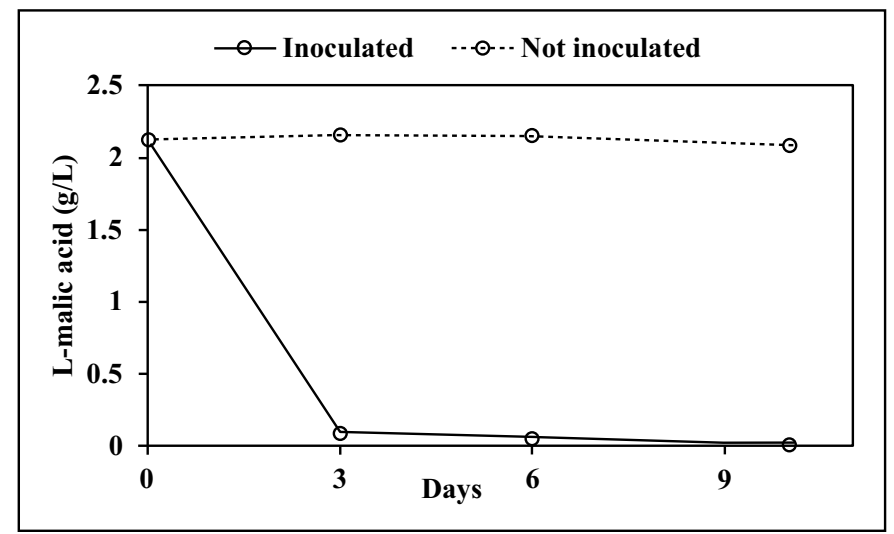

Fig. (1). Trends in L-malic acid concentration into inoculated and not inoculated substrates. Each point represents mean value; error bars indicate \pm standard deviations.

The OTA content (Fig. 2) decreased only in the L-malic+ medium and only in the first 3 days after inoculum. OTA levels in L-malic- and in the control samples were statistically comparable and did not significantly change through the time, indicating that OTA reduction was linked to both bacteria and L-malic acid presence.

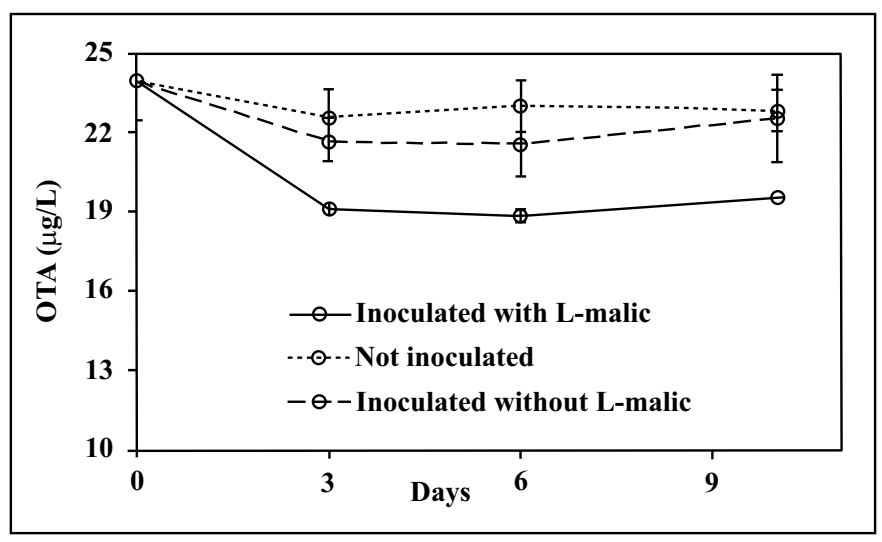

Fig. (2). Trends in OTA concentration into inoculated substrates with and without L-malic acid, and into not inoculated substrate. Each point represents mean value, error bars indicate \pm standard deviations.

OTA reduction in the L-malic + medium was $19.5 \pm 2.0 \%$. This limited decrease could be related both to the unfavourable YNB composition and to the high applied initial OTA concentration $(25 \mu \mathrm{g} / \mathrm{L})$, although the positive control $B$. linens showed a total degradation of OTA after three days confirming the results of Rodriguez et al. [16] (data not showed). Our results agree with Piotrowska \& Żakowska [6] who proved that high OTA levels have a 
negative effect on the LAB growth. However, Abrunhosa et al. [17] observed an OTA degradation by Pediococcus, Lactobacillus and Oenococcus on Man Rogosa Sharpe (MRS) with an initial OTA level of $1000 \mu \mathrm{g} / \mathrm{L}$, showing that LAB can grow also in the presence of high OTA concentration.

OTA distribution between supernatant and pellet was also investigated, showing that just a little amount of OTA $(0.7 \pm 0.2 \%)$ remained bound to the bacteria walls in the L-malic + samples. This value was comparable with the $1.3 \pm$ $1.0 \%$ of adsorbtion on cells of P. parvulus described by Abrunhosa et al. [17] and confirm that in our trials the adsorption mechanism cannot explain the observed OTA reduction. Regarding this point, it could also be assumed that high stress conditions, caused by lack of nutrients, led to cell lysis processes (as indicated by the decrease in $\mathrm{OD}_{630}$ ) with potential reduction of available surface for the adsorption and release in the media of the already adsorbed toxin [3, 18].

Since OTA biodegradation process was evident only in the presence of L-malic acid, it can be said that the OTA cannot be used as a carbon source unless another carbon source is present and that its metabolization is related to bacteria viability.

One hypothetical metabolic pathway for OTA metabolism could be the hydrolysis of peptide bond to form OT $\alpha$ and L- $\beta$-phenylalanine. The initial OTA concentration of $25 \mu \mathrm{g} / \mathrm{L}$ was selected to better detect the hypothetical OT $\alpha$ production. However, OT $\alpha$ could not be detected neither in supernatants nor in the biomass pellets, in agreement with [17].

Based on this finding other mechanisms of OTA degradation, without OT $\alpha$ production, as opening of the isocoumarin ring in a ring-opened lactone form of OTA, or dechlorination from OTA to OTB [19] must be identified.

\section{CONCLUSION}

L. plantarum V22 strain proved to reduce OTA into synthetic medium only when L-malic acid was present even though as the only carbon source. This underlines the potential of exploiting this strain to combine malolactic fermentation with OTA reduction in wine-making. OTA showed a reduction of $19.5 \pm 2.0 \%$ with a negligible amount of OTA adsorbed on bacterial cell wall $(0.7 \pm 0.2 \%)$ indicating a biological degradation. Lack of OT $\alpha$ in supernatant and in pellet led to suppose that OTA reduction is not associated with the presence of enzymes able to hydrolyse the amine bond between L- $\beta$-phenylalanine and isocoumarinic part (i.e. carboxipeptidase), therefore a different metabolic pathway must be involved which needs further investigations. As commented by [20], the current climate change scenarios may lead to modifications in fungal species distribution, as well as in ochratoxin occurrence in wine, therefore biodetoxification methods, such as the exploitation of selected lactic acid bacteria for malolactic fermentation, will be important.

$\begin{array}{lll}\text { ABBREVIATIONS } & & \\ \text { OTA } & = & \text { OchraToxin A } \\ \text { LAB } & = & \text { Lactic Acid Bacteria } \\ \text { OT } \alpha & = & \text { Ochratoxin } \alpha \\ \text { MLF } & = & \text { Malolactic Fermentation } \\ \text { YNB } & = & \text { Yeast Nitrogen Base }\end{array}$

ETHICS APPROVAL AND CONSENT TO PARTICIPATE

Not applicable.

\section{HUMAN AND ANIMAL RIGHTS}

No animals/humans were used for studies that are the basis of this research.

\section{CONSENT FOR PUBLICATION}

Not applicable.

\section{CONFLICT OF INTEREST}

The authors declare no conflict of interest. The authors acknowledge the Agrisystem Ph.D School of the Università Cattolica del Sacro Cuore (Italy) for the Ph.D fellowship to the author Moncalvo A. 


\section{REFERENCES}

[1] IARC (International Agency for Research on Cancer). Some Naturally Occurring Substances, Food Items and Constituents, Heterocyclic Aromatic Amines and Mycotoxins. Monographs on the Evaluation of Carcinogenic Risks to Humans 2003;56, Lyon, France.

[2] Zimmerli B, Dick R. Ochratoxin A in table wine and grape-juice: Occurrence and risk assessment. Food Addit Contam 1996; 13(6): 655-68. [http://dx.doi.org/10.1080/02652039609374451] [PMID: 8871123]

[3] Del Prete V, Rodriguez H, Carrascosa AV, de las Rivas B, Garcia-Moruno E, Muñoz R. In vitro removal of ochratoxin A by wine lactic acid bacteria. J Food Prot 2007; 70(9): 2155-60. [http://dx.doi.org/10.4315/0362-028X-70.9.2155] [PMID: 17900096]

[4] Garcia-Moruno E, Sanlorenzo C, Beccaccino B, Di Stefano R. Treatment with yeast to reduce the concentration of ochratoxin A in red wine. Am J Enol Vitic 2005; 56: 73-6.

[5] Grazioli B, Fumi MD, Silva A. The role of processing on ochratoxin A content in Italian must and wine: A study on naturally contaminated grapes. Int J Food Microbiol 2006; 111(Suppl. 1): S93-6.

[http://dx.doi.org/10.1016/j.ijfoodmicro.2006.01.045] [PMID: 16714068]

[6] Piotrowska M, Żakowska Z. The elimination of ochratoxin A by lactic acid bacteria strains. Pol J Microbiol 2005; 54(4): $279-86$. [PMID: 16599298]

[7] Muñoz K, Blaszkewicz M, Degen GH. Simultaneous analysis of ochratoxin A and its major metabolite ochratoxin alpha in plasma and urine for an advanced biomonitoring of the mycotoxin. J Chromatogr B Analyt Technol Biomed Life Sci 2010; 878(27): $2623-9$. [http://dx.doi.org/10.1016/j.jchromb.2009.11.044] [PMID: 20031488]

[8] Moncalvo A, Marinoni L, Dordoni R, Duserm Garrido G, Lavelli V, Spigno G. Waste grape skins: Evaluation of safety aspects for the production of functional powders and extracts for the food sector. Food Addit Contam Part A Chem Anal Control Expo Risk Assess 2016; 33(7): 1116-26.

[http://dx.doi.org/10.1080/19440049.2016.1191320] [PMID: 27295010]

[9] Fumi MD, Silva A, Krieger S, Vagnoli P, Domeneghetti D. Applicabilità di preparati liofilizzati di Lactobacillus plantarum per il controllo della fermentazione malolattica in mosti/vini con alti valori di pH. Paper presented at the Enoforum 2009, Piacenza.

[10] Bornet A, Teissedre PL. Reduction of toxins and contaminants with biological tools. Bull OIV 2007; 80: 471-81.

[11] Castellari M, Versari A, Fabiani A, Parpinello GP, Galassi S. Removal of ochratoxin A in red wines by means of adsorption treatments with commercial fining agents. J Agric Food Chem 2001; 49(8): 3917-21. [http://dx.doi.org/10.1021/jf010137o] [PMID: 11513689]

[12] Silva A, Galli R, Grazioli B, Fumi MD. Metodi di riduzione di residui di ocratossina A nei vini. Ind Bevande 2003; 32: 467-72.

[13] Bejaoui H, Mathieu F, Taillandier P, Lebrihi A. Ochratoxin A removal in synthetic and natural grape juices by selected oenological Saccharomyces strains. J Appl Microbiol 2004; 97(5): 1038-44.

[http://dx.doi.org/10.1111/j.1365-2672.2004.02385.x] [PMID: 15479420]

[14] Shetty PH, Jespersen L. Saccharomyces cerevisiae and lactic acid bacteria as potential mycotoxin decontaminating agents. Trends Food Sci Technol 2006; 17: 48-55. [http://dx.doi.org/10.1016/j.tifs.2005.10.004]

[15] Nunez YP, Pueyo E, Carrascosa AV, Martínez-Rodríguez AJ. Effects of aging and heat treatment on whole yeast cells and yeast cell walls and on adsorption of ochratoxin A in a wine model system. J Food Prot 2008; 71(7): 1496-9.

[http://dx.doi.org/10.4315/0362-028X-71.7.1496] [PMID: 18680954]

[16] Rodriguez H, Reveron I, Doria F, et al. Degradation of ochratoxin a by Brevibacterium species. J Agric Food Chem 2011; 59(19): 10755-60. [http://dx.doi.org/10.1021/jf203061p] [PMID: 21892825]

[17] Abrunhosa L, Inês A, Rodrigues AI, et al. Biodegradation of ochratoxin A by Pediococcus parvulus isolated from Douro wines. Int J Food Microbiol 2014; 188: 45-52.

[http://dx.doi.org/10.1016/j.ijfoodmicro.2014.07.019] [PMID: 25087204]

[18] Haskard CA, El-Nezami HS, Kankaanpää PE, Salminen S, Ahokas JT. Surface binding of aflatoxin B(1) by lactic acid bacteria. Appl Environ Microbiol 2001; 67(7): 3086-91. [http://dx.doi.org/10.1128/AEM.67.7.3086-3091.2001] [PMID: 11425726]

[19] Li S, Marquardt RR, Frohlich AA. Identification of ochratoxins and some of their metabolites in bile and urine of rats. Food Chem Toxicol 2000; 38(2-3): 141-52.

[http://dx.doi.org/10.1016/S0278-6915(99)00153-2] [PMID: 10717354]

[20] Gil-Serna J, Vázquez C, González-Jaén MT, Patiño B. Wine contamination with Ochratoxins: A Review. Beverages 2018; 4(6): 1-21.

(C) 2018 Moncalvo A. et al.

This is an open access article distributed under the terms of the Creative Commons Attribution 4.0 International Public License (CC-BY 4.0), a copy of which is available at: (https://creativecommons.org/licenses/by/4.0/legalcode). This license permits unrestricted use, distribution, and reproduction in any medium, provided the original author and source are credited. 